Neurosurg Focus 24 (1):E3, 2008

\title{
The pathogenesis of ankylosing spondylitis
}

\author{
Mohammed F. ShamjI, M.D., M.Sc., Mohammed Bafaquh, M.D., \\ and Eve Tsai, M.D., PH.D. \\ Division of Neurosurgery, The Ottawa Hospital and University of Ottawa, Canada
}

\begin{abstract}
$\checkmark$ Ankylosing spondylitis (AS) is a chronic inflammatory disease that can cause significant functional complications by affecting the sacroiliac joints and axial skeleton. Despite a longstanding knowledge about the familial associations of this disease, particularly among patients positive for human leukocyte antigen (HLA)-B27, the fundamental pathogenetic mechanism by which this disease arises in genetically susceptible individuals remains ill defined. Furthermore, the molecular predilection for characteristic articular site involvement remains under ongoing investigation. Current theories about the HLA-B27 association range from the presentation of novel arthritogenic peptides, to abnormal autoimmune stimulation, to anomalous microbial tolerance. The immune effectors of this damage include CD4+, CD8+, and natural killer cells, with marked heterogeneity at different sites. Biomechanical stresses may trigger this disease by exposing the body to previously immune-sequestered autoantigens or by providing a route for bacterial seeding. Environmental triggers such as infection have not been definitively established but may represent a primary pathogenic step in a molecular-mimicry process. In this article, the authors review the current literature on the origin and pathophysiology of AS, focusing on genetic and molecular associations, consequent pathomechanisms, and associated triggers. An improved understanding of the sequence of molecular events that predispose and initiate the onset of this disease will allow for more specific and targeted therapy and better avoidance of the significant side effects of systemic immunomodulation. (DOI: 10.3171/FOC/2008/24/1/E3)
\end{abstract}

\section{KEY WORDS • ankylosing spondylitis pathophysiology}

A NKYLOSING spondylitis is a chronic inflammatory disease that primarily affects the sacroiliac joints and the axial skeleton. It is generally considered to be the archetypal seronegative spondyloarthropathy. While there is considerable ethnic and geographic variation in the prevalence of AS, the strong familial associations of this disease, particularly among patients positive for HLA-B27, have implicated a role for an immunogenetic abnormality in the pathogenesis. Despite significant advances in the diagnosis and management of AS, there continues to be much uncertainty concerning the specific genetic predispositions and environmental triggers that result in this disease. An improved understanding of the sequence of molecular events that predispose and initiate the onset of this disease will allow more specific and targeted therapy with avoidance of the significant side effects of systemic im-

Abbreviations used in this paper: AAU = acute anterior uveitis; $\mathrm{AS}=$ ankylosing spondylitis; $\mathrm{ER}=$ endoplasmic reticulum; ERAD = endoplasmic reticulum-associated degradation; HLA = human leukocyte antigen; HSP = heat shock protein; IFN = interferon; IL = interleukin; MHC = major histocompatibility complex; $\mathrm{MMP}=$ matrix metalloproteinase; $\mathrm{NK}=$ natural killer; TGF = transforming growth factor; TNF = tumor necrosis factor; UPR = unfolded protein response. munomodulation. We review the current literature on the pathophysiology of AS, focusing on genetic and molecular associations, consequent pathomechanisms, and associated environmental triggers. The pathological features of AS are also reviewed.

\section{Genetic Associations and Molecular Pathogenetic Mechanisms}

The predominant genetic association with AS is the MHC group of molecules, specifically HLA-B27. There are significant associations of AS with HLA-B27, and the estimated overall contribution to AS susceptibility is estimated to be between 20 and $40 \%$. We will review the HLA$\mathrm{B} 27$, other MHC, and non-MHC genetic associations with $\mathrm{AS}$, and examine the pathogenetic mechanisms and the cytokine and enzyme effectors of inflammation. An understanding of these genes and their protein products (Table 1) provides insight into the underlying disease pathogenesis and may permit the development of novel avenues of treatment.

Human Leukocyte Antigen-B27

Human leukocyte antigen-B27 is an MHC Class I mol- 
TABLE 1

Genetic associations with ankylosing spondylitis

\begin{tabular}{ll}
\hline \hline \multicolumn{1}{c}{ Gene Group } & Products \\
\hline HLA-B27 & HLA-B27 \\
non-HLA-B27 MHC genes & HLA-B60 \\
& HLA-B61 \\
& HLA-DRB1*01, B1*04 \\
& HLA-DR8 \\
& LMP-2, LMP-7 \\
& HSP-70 \\
& IL-1 gene cluster \\
non-MHC genes & CYP2D6 \\
& TGF 3 \\
\hline
\end{tabular}

ecule that is encoded on chromosome 6; although it is ubiquitous among cell types, its expression is higher on antigenpresenting cells. After translation and tertiary folding, this protein binds to $\beta_{2}$-microglobulin and is loaded with an oligopeptide. These peptides are normally derived from self-proteins, but antigenic peptides may be displayed when intracellular microbes infect the cell. The trimolecular complex travels through the Golgi apparatus to the cell surface where the antigenic peptide is presented to CD8+ lymphocytes or NK cells. Human leukocyte antigen-B27 also has associations with other spondyloarthropathies, including reactive arthritis, psoriatic arthritis, and anterior uveitis. There is a strong genetic association between HLA$\mathrm{B} 27$ and AS, with the protein isoform found in more than 90\% of afflicted patients ${ }^{19,92,99}$ however, fewer than $5 \%$ of HLA-B27+ individuals will develop AS..$^{14,111}$

The fact that only a small proportion of people positive for $H L A-B 27$ develop AS may be attributable to the different allele types that exist. There are at least 25 allele subtypes of $H L A-B 27$ that encode 23 different gene products. The most common subtype $(B * 2705)$ is thought to be the parent molecule from which the other types have evolved and is the most closely associated with the risk of AS. ${ }^{6}$ Other subtypes that confer disease susceptibility include $\mathrm{B} * 2701, \mathrm{~B} * 2702, \mathrm{~B} * 2704$, and $\mathrm{B} * 2707$, whereas the B*2706 and B*2709 alleles that are common in Southeast Asia and Sardinia do not have an association with AS. ${ }^{6}$

Another explanation for disease susceptibility in certain HLA-B27+ individuals may be the expression levels in antigen-presenting cells. Human leukocyte antigen-B27 has been found to be more highly expressed in peripheral blood mononuclear cells in HLA-B27+ patients with AS than in healthy HLA-B27+ individuals. ${ }^{27}$ Furthermore, expression levels were found to be higher in AS patients with $\mathrm{B} * 2705$ than in healthy individuals with $\mathrm{B} * 2709$ and $\mathrm{B} * 2705$.

\section{The Role of HLA-B27 in AS}

Several theories have been promoted with regard to the molecular pathogenetic role of HLA-B27 in AS. These include the presentation of arthritogenic peptides, aberrant folding of surface heavy chains, HLA-B27 misfolding, and enhanced intracellular microbial survival. ${ }^{91}$ These mechanisms are summarized in Table 2 and explained in the following sections.

Presentation of Arthritogenic Peptides. Human leukocyte antigen-B27 may have the ability to bind unique antigenic
TABLE 2

Role of HLA-B27 in pathogenesis of ankylosing spondylitis

\begin{tabular}{lll}
\hline \hline \multicolumn{1}{c}{ Hypothesis } & Pathogenic Site & Immunity \\
\hline arthritogenic peptide presentation & immunological & adaptive \\
aberrant surface heavy chain & immunological & innate \\
abnormal protein folding & intracellular & innate \\
enhanced microbial survival & intracellular & innate \\
\hline
\end{tabular}

peptides, ${ }^{38,40,62-65}$ leading to the CD8+ cytotoxic T-cell responses to these self or bacterial sequences. The ensuing cytolytic response leads to tissue injury and diffuse inflammation. Unlike most other MHC Class I molecules, there is a restriction for peptides with arginine at the $\mathrm{P} 2$ position to bind to HLA-B27.55,74,75 Single amino acid changes from aspartate in the $\mathrm{B} * 2705$ allele to histidine in the $\mathrm{B} * 2709$ allele leads to a loss of the association with AS. ${ }^{31}$ Thus, the correlation with AS may result from the B*2705 allotype's differential peptide-binding repertoire. ${ }^{89}$ In general, subtypes not associated with AS have a restriction for nonpolar c-terminal residues such as aliphatic chains and phenylalanine, whereas disease-associated molecular subtypes are able to bind peptides with a c-terminal tyrosine. ${ }^{72}$

The identity of the specific arthritogenic peptide in AS remains elusive. In support of molecular mimicry eliciting an untoward inflammatory reaction, Scofield and coworkers $^{100}$ have identified a nonapeptide of sequence LRRY LENGK that occurs both in HLA-B27 heavy chains and enteric bacteria. This nonapeptide has been demonstrated to be recognized by the peripheral blood lymphocytes of patients with AS who are positive for $H L A-B 27$, but not by healthy individuals positive for $H L A-B 27.44$ Authors of molecular modeling studies have proposed that free HLAB27 heavy chains can undergo backbone rotation to permit residues $169-181$ to occupy its own binding groove. ${ }^{73}$ Presentation of this epitope, either within or between HLAB27 molecules, could elicit an autoimmune reactivity. Another self-peptide that has received attention is a 9 amino acid fragment of VIPIR (residues 400-408), a sequence highly homologous to an Epstein-Barr virusderived epitope of latent membrane protein 2 (residues 236-244). Although the CD8+ T-cell response to VIPIR was greater in AS patients than in controls,${ }^{39}$ both the HLAB27 subtypes with $(B * 2705)$ and without $(B * 2709)$ the AS association could present this molecule. However, crystallographic evidence suggests that while B*2709 can bind the fragment in the conventional binding groove, $\mathrm{B} * 2705$ can additionally present the peptide in a second conformation creating a salt-bridge with the differing aspartate-116 residue ${ }^{40}$ In addition, the LMP 2 protein can also be uniquely presented in a nonconventional conformation by $\mathrm{B} * 2705$.

Proteomic analysis has also been used to evaluate human serum protein binding to HLA-B27 in 7 patients with AS and 7 healthy controls from the same Chinese family. ${ }^{70}$ Four isoforms of prehaptoglobin were found to be highly expressed in all the study patients with active disease. The decapeptide VRYQCKNYYK was predicted to have a much higher binding affinity to HLA-B27 than conventional epitopes, and so it was concluded that prehaptoglobin is involved in the pathogenesis of AS. However, this 
study was limited in that only the serum proteome was evaluated, while the high specificity of AS for specific tissues suggests that the differential protein expression in those tissues may demand investigation. Although these observations do not conclusively implicate any of these potential antigens, they do suggest a molecular mechanism by which disease-associated HLA-B27 subtypes may become pathogenic.

Another antigen of specific interest is aggrecan, a large aggregating chondroitin sulfate proteoglycan. A strong cellular immune response against the G1 domain of aggrecan has been noted in patients with AS, with 62 and $72 \%$ of patients having circulating and synovial CD4+ T cells with specificity for this antigen. The ability of the intervertebral disc to resist compression is in part due to the high aggrecan content whose hydration provides for osmotic pressure. The entheses, anterior uveal tract, aorta, and aortic valve all contain aggrecan or homologous proteins such as versican that provide for cyclic compression and relaxation. Immunity to aggrecan in BALB/c mice induces spondylitis and peripheral arthritis, ${ }^{45}$ and the immunoreactive G1 domain is the major proteolytic degradation product of the proteoglycan. One explanation for these findings is that fibrocartilaginous entheseal microtrauma or local inflammatory processes secondary to infection in the immunogenetically predisposed patient may lead to an autoimmune reaction against newly exposed antigens that are also expressed at extraarticular sites typical of AS. Another potential explanation is that the $\mathrm{G} 1$ domain could induce antigen-specific tolerance with consequent suppression of the normal eradication mechanisms of inflammatory foreign material. A third possibility is that there may be no immunopathological role, with anti-G1 reactivity occurring as a secondary event after cartilage destruction caused by another primary process.

Aberrant Surface Heavy Chains. Although arthritogenic protein presentation may play a role in the pathogenesis of AS, this may not be the unique pathogenetic mechanism by which AS-associated HLA-B27 subtypes mediate disease. The T-cell-dependent development of colitis and arthritis in transgenic HLA-B27 rats is unchanged by CD8+ T-cell depletion, thus raising the question of whether other autoinflammatory pathways are invoked in this disease. ${ }^{81} \mathrm{Ab}$ errant folding of HLA-B27 molecules can lead to unusual molecular conformations, and these nonconventional forms may trigger pathogenic autoinflammatory activity. In vitro folded HLA-B27 in the absence of $\beta_{2}$-microglobulin had a propensity to form disulfide-bridged homodimers using an unpaired cysteine residue. ${ }^{1}$ Although these dimers normally form when cell surface heavy chains lose $\beta_{2}$-microglobulin during endosomal recycling, free monomeric HLA-B27 heavy chains have been observed from which surface dimerization is possible. The immunological consequence of these abnormal linkages has been studied using tetramerized dimers, with 1 receptor (KIR3DL2) specifically recognizing the supramolecular complex..$^{58,59}$ Higher frequencies of KIR3DL2+ NK and CD4+ T cells have been found in patients with spondyloarthropathies. ${ }^{28}$ More recently, the HLA-B27 homodimer recognition by KIR3DL2+ NK and CD4+ T cells has been found to be independent of the bound peptide sequence. ${ }^{60}$ This nonconventional display of dimerized HLA-B27 can have the im- munological consequence of eliciting unnecessary and destructive NK and CD4+ T-cell effector function autoreactivity, thereby triggering the disease process. The specific subtype of CD4+ T cells expanded among AS patients is CD28-, and this subtype has also been described as involved in other chronic inflammatory conditions such as Wegener granulomatosis, rheumatoid arthritis, and multiple sclerosis. ${ }^{32}$ These CD28- cells can sustain synovitis through the release of IFN $\gamma$ and can also lyse target cells by releasing perforin.

Protein Misfolding. One fate of misfolded proteins is that they are degraded by the process of ERAD. If the capacity of cells to process the misfolded proteins through ERAD is exceeded, then these misfolded proteins may be deposited as intra- or extracellular aggregates. These aggregates are frequently toxic and can elicit nonspecific inflammatory reactions by mononuclear cells. The HLA-B*2705 polypeptide sequence has been shown to undergo slower protein folding and greater cytosolic accumulation than non-disease-prone HLA types. ${ }^{84}$ There are various characteristics of the HLA-B*2705 polypeptide sequence that may contribute to such folding abnormalities. Abnormal tertiary protein folding with erroneous intramolecular disulfide bridging can occur, and this can be compounded by erroneous quaternary interactions of intermolecular covalent bond formation. Whereas the cell surface contains $\sim 6 \%$ HLA-B27 homodimers, $\geq 25 \%$ of heavy chains in the ER are disulfide bridged. ${ }^{30}$ The cysteine- 67 residue is implicated in this process, however, the identity of other residues in the binding groove influences appropriate folding. Specifically glutamate-45 is most detrimental to efficient protein folding, and lysine-70 increases the reactivity of the unpaired cysteine residue promoting supramolecular association. ${ }^{118}$

Another response to misfolded proteins is the UPR. ${ }^{50}$ When the ER is stressed in cells expressing the aberrant protein, the cell can activate signaling cascades that attempt to deal with the altered condition and restore a favorable protein folding environment. ${ }^{65}$ Macrophages derived from bone marrow of transgenic HLA-B27+ rats treated with IFN $\gamma$ showed evidence of the UPR, whereas this response was absent in nontransgenic and non-disease-prone transgenic rats. ${ }^{110}$ This effect correlates with increased HLAB27 expression, increased formation of misfolded heavy chains, and increased occupancy of the ER-resident chaperone protein, BiP. Heightened and prolonged interaction between HLA-B27 and BiP leads to simultaneous activation of ERAD and proinflammatory NF-к $\beta$ pathways. These are important responses of HLA-B27 biological inflammatory activity in the absence of specific immune recognition. In the same study, inflamed tissue from the gastrointestinal tract exhibited the same UPR activation; curiously this effect was not seen in other tissues such as the thymus and spleen, even in animals with active disease. Of further pathogenetic interest is that these transgenic rats undergoing the UPR exhibited synergistic induction of IFN $\beta$ in response to lipopolysaccharide. ${ }^{101}$ The implications of this mechanism include activation of NK cells and macrophages, promotion of T-cell survival, and induction of dendritic cell maturation. ${ }^{68,108}$ This process is antigen-independent with activated macrophages secreting cytokines that augment inflammatory cell infiltration and MMPs that 
can cause local tissue destruction. The latter may release antigens that can then become targets of a specific T-cell immune response. Although IFN $\beta$ is also known to inhibit osteoclast activity, ${ }^{103,104}$ its role in the aberrant bone formation of AS remains unclear.

Enhanced Intracellular Microbial Survival. Enhanced intracellular microbial survival may also play a role in the pathogenesis of AS. Abnormal immune system activation or modulation can occur because of ineffective peptide loading onto HLA-B27, leading to excessive viral or intracellular bacterial proliferation and delayed antigenic peptide clearance. There is conflicting evidence to support this claim, however transfected monocytes do exhibit an enhanced survival of Salmonella enteritidis, ${ }^{88}$ possibly because of a dysregulated p38 mitogen-associated protein kinase function. Conversely, clearance of Salmonella from intestinal epithelial cells $s^{96}$ and synoviocytes ${ }^{52}$ seems to be unaffected under nonactivated conditions, but synoviocyte coincubation with IFN $\gamma$ did create a permissive environment for intracellular bacteria. This permissive environment may be the result of the decreased TNF $\alpha$ - and IFN $\gamma$ producing cells among patients with AS, with a decreased helper T-cell (Th1) response, leading to the impaired containment and eradication of the intracellular pathogens. ${ }^{95}$

An alternate proposed mechanism conferring survival is the expansion of NK cells expressing the NK-inhibitory receptor carcinoembryonic antigen-cell adhesion molecule (CEACAM1). Natural killer cells from patients with AS and from healthy individuals reacted with HLA-B27, although the higher level of CEACAM1 expression among those with AS made these patients susceptible to ligandmediated inhibition. ${ }^{4}$ The attenuated cytolytic activity of these cells may contribute to the prolonged survival of the antigenic, proinflammatory stimulus.

\section{Evidence of Other Genetic Associations in AS}

There is significant evidence to suggest that other genetic factors act to determine which of these patients have a heightened susceptibility to developing the disease, and family studies consistently show that HLA-B27+ patients who have a first-degree relative with AS have rates of disease development 6-16 times greater than those without such a family history. ${ }^{26,111}$ Twin studies further demonstrate this with AS concordance rates for monozygotic twins of $75 \%$, for dizygotic twins of $12.5 \%$, and for HLA-B27+ dizygotic twins of $27 \% .{ }^{24}$ In addition to incidence, Hamersma et al. ${ }^{49}$ have assessed clinical severity using the Bath AS disease activity index and the Bath AS functional index and have reported heritability of 51 and $68 \%$ respectively. ${ }^{49}$ Furthermore, the radiographic severity assessed with the Bath AS radiographic index has a heritability index of $0.62 .{ }^{20}$ Because all of the patients in these studies were HLA-B27+, the observed variation in heritability reaffirms the role of non-HLA-B27 factors in clinical phenotype. ${ }^{21}$

\section{Other MHC Associations}

Given that $10 \%$ of Caucasian patients with AS are HLAB27-, investigation into other MHC components has yielded information about other molecular associations of this disease. In both Caucasian and Taiwanese Chinese populations, carriage of HLA-B60 and HLA-B61 has been shown to be increased in patients with AS, independent of HLAB27 status. ${ }^{25,115}$ The peptide-binding motif of HLA-B60 is reportedly substantially different from HLA-B27;36 however, the similar T-cell epitopes of both HLA-B60 and HLAB61 with HLA-B27 supports a molecular mimicry mechanism..$^{71}$

Various other MHC-related genes have been demonstrated to have an association with AS, but the putative mechanisms by which they are involved remain undefined. Class II MHC alleles such as HLA-DRB1*01 and DRB1 *04 have also been associated with AS incidence, although not with disease severity or clinical manifestation. ${ }^{23,98} \mathrm{~A}$ study of 42 Japanese patients with AS reported that HLADR8 augments susceptibility to uveitis. ${ }^{87}$ Low molecular weight proteasome (LMP) genes 2 and 7 encode subunits of a multicatalytic enzyme that degrades cytoplasmic proteins into oligopeptides that are eventually loaded onto MHC-I complexes. Several studies have reported that specific LMP2 $2^{12}$ and $\mathrm{LMP}^{42}$ alleles increase susceptibility to AS and the likelihood of developing the extraarticular symptoms of AAU..$^{77,78}$ One study in 150 Mexican patients suggests an association of several HSP70 gene polymorphisms with AS. ${ }^{113}$ Although HSP70-2 and HSP70-hom were found to have a significant association with AS in patients both positive and negative for HLA-B27, such findings were not replicated in studies of Finnish or Spanish patients. ${ }^{41,117}$ There is currently no proposed mechanism linking HSP allelic differences with autoimmune disease.

\section{Non-MHC Genetic Associations}

Genomic screening has yielded evidence for non-MHC genetic contributions to the development of AS. Wholegenome screening in 185 families with AS and 255 affected sibling pairs revealed that the strongest linkage was found on chromosome arm 16q (logarithm of the odds score of 4.7) ${ }^{67}$ Other regions with moderate evidence of linkage exist on chromosomes 3,10 , and 19, and nominal linkage was demonstrated on chromosome arms $2 \mathrm{q}$ and 22q. Other authors have described the specific non-MHC genes associated with AS to include the IL-1 gene complex, cytochrome P450 2D6 (CYP2D6), and TGF $\beta .^{21}$

The IL-1 complex encodes proinflammatory cytokines IL- $1 \alpha$ and IL-1 $\beta$ on chromosome 2 . There is widespread association with AS across the IL-1 gene cluster. The most implicated region encodes IL- $1 \alpha$, although the specific variants that cause disease remain unidentified. ${ }^{109}$ Interleukin-1 receptor antagonist (IL-1Ra) shares some sequence homology as a competitive cytokine receptor antagonist, and various single nucleotide polymorphisms are also associated with $\mathrm{AS} .{ }^{76}$ Of mechanistic interest is that various clinical studies demonstrate that inhibition of IL-1 activity by recombinant human IL-1Ra in patients with nonsteroidal antiinflammatory drug-resistant disease leads to limited improvement in both clinical ${ }^{48}$ and radiographic $^{105}$ evaluations.

The CYP2D6 gene, encoded at 22q13, is a mixed-function oxidase implicated in the metabolism of xenobiotics. Loss of function mutations that decrease oxidative drug metabolism occur in 5-10\% of Caucasians, with a lower incidence in other ethnic groups such as Asians (2\%). Such mutations have been reported by several authors to be asso- 
ciated with AS, ${ }^{10,22}$ with a hypothesized mechanism of reduced metabolism of the natural antigens or toxins that may trigger the disease onset.

Involvement of TGF $\beta$ has been suspected based on its location on chromosome arm $19 \mathrm{q}$, a region with moderate linkage in whole-genome screening, as well as on its functional involvement in inflammation, tissue fibrosis, and bone remodeling. Two single nucleotide polymorphisms that have received attention include TGFBI+915 and TGFBI+1632. Both polymorphisms have been associated with disease incidence, and the former is also reported to yield higher circulating levels of this anabolic protein. ${ }^{54}$ High circulating TGF $\beta$ levels have also been observed by other groups ${ }^{51}$ but the mechanism and impact of this cytokine imbalance remain unclear.

\section{Cytokine and Enzyme Effectors}

The immunopathogenesis of AS is suspected to involve downstream upregulation of proinflammatory cytokines. Tumor necrosis factor $-\alpha$ is consistently found to be more highly expressed in patients with AS than in healthy individuals,${ }^{5,47}$ and there is evidence that anti-TNF $\alpha$ therapies can effectively improve both clinical and laboratory disease parameters. ${ }^{12,15-17,116}$ Heightened serum levels of IL-6 and soluble IL-2 receptor have been found in patients with AS, and the latter was shown to have a positive association with fatigue and pain scores and with the Bath AS Functional and Metrology Indices. ${ }^{5}$

Many cell lines produce MMPs in response to proinflammatory cytokines such as TNF $\alpha$ and IL-1, and these Zinc-dependent endopeptidases normally play an important role in the degradation of the extracellullar matrix. Excessive proteolysis in the inflamed joint can result from a pathological imbalance between MMPs and their inhibitors, and a higher expression of MMP-3 has been found among patients with AS, ${ }^{29}$ with quantitative levels positively correlating with both the Bath AS Disease Activity and Functional Indices. Matrix metalloproteinase-3 has been advocated as a biomarker of disease activity that is more accurate than erythrocyte sedimentation rate or C-reactive protein levels. The putative roles of MMP-3 include the primary digestion of extracellular matrix components and enzymatic activation of various other pro-MMPs to induce further proteolytic activity. ${ }^{114}$

\section{Environmental Triggers}

Although various other spondyloarthropathies have been linked to infectious origins, the role of microbial pathogenesis in the development of AS has remained undefined. Animal studies have shown that the genetically susceptible HLA-B27-transgenic rats only exhibit the disease phenotype on exposure to a pathogen, ${ }^{107}$ but less definitive evidence exists among human patients, and no organism has been identified in synovial fluid and sacroiliac joints. ${ }^{18} \mathrm{Cir}-$ cumstantial evidence of microbial involvement has been borne out in demographic studies suggesting higher rates of enteric infection among patients with AS and undifferentiated spondyloarthropathy who have active disease. ${ }^{80}$ There are specific bacterial agents with an established relation- ship to HLA-B27, and these include Campylobacter, Chlamydia, Shigella, Salmonella, Yersinia, and Klebsiella. $^{33,61,69,102}$

Of specific interest is Klebsiella pneumoniae infection as a triggering or perpetuating factor in the pathogenesis of AS through the mechanism of molecular mimicry. There is significant sequence homology for a hexapeptide epitope (QTDRED) in HLA-B27 and Klebsiella nitrogenase reductase ${ }^{53}$ There is a further tetrapeptide homology for HLAB27 and the Klebsiella pullulanase Pul-D domain, and tripeptide homology for Types I, III, and IV collagens and Klebsiella pullulanase Pul-A domain. ${ }^{37}$ Antibodies to such epitopes are cross-reactive with synovial tissues from HLA-B27+ patients..$^{90}$ There are several lines of evidence that suggest that Klebsiella, and not other microbes, is responsible for AS.$^{90}$ Klebsiella microbes have been isolated in more than $70 \%$ of AS patients with AAU, ${ }^{34}$ and elevated levels of anti-Klebsiella antibodies have also been detected in these patients. ${ }^{97}$ In addition, patients with biochemically inactive AS, as assessed by normal erythrocyte sedimentation rate and C-reactive protein levels, do not have elevated antibody titers against Klebsiella. ${ }^{106}$ The antibodies against Klebsiella produced in the gut could bind to cross-reactive antigens in the nearby joints and via the Batson plexus to the lumbar spine. The increased prevalence of AS in young adult males may result from a higher starch intake and consequent increase in Klebsiella growth in the gut. ${ }^{2}$ The site at which the triggering infection occurs is unclear, but the presence of histological signs of inflammation $^{86}$ and increased gut permeability ${ }^{79}$ in patients with AS suggests an overt or occult enteric infection.

\section{Pathological Features of AS}

Inflammation in AS occurs primarily at the sacroiliac joints, but can involve entheses, vertebral bodies adjacent to the intervertebral discs, and peripheral joint synovium. The extraarticular pathological features include involvement of the ophthalmic, cardiovascular, pulmonary, gastrointestinal, and renal systems, and are summarized in

TABLE 3

Extraarticular features of AS

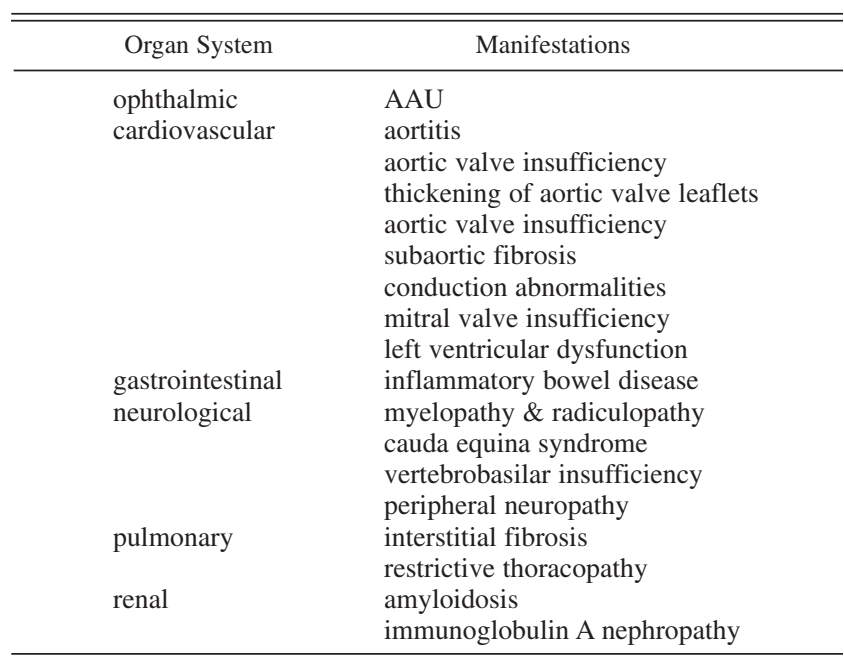


Table 3. In the present study, our discussion is limited to addressing the spinal and articular pathological characteristics of AS.

In AS, the apophyseal, costovertebral, and sacroiliac joints of the axial skeleton are most typically affected and may ultimately become ankylosed. The enthesitis that is typical of AS occurs at fibrocartilaginous sites, with the enthesis originating at the cartilage and attaching at the epiphyses or apophyses. Affected entheseal fibrocartilage structures are generally exposed to significant shear stress and microtrauma, and it is suspected that this pathomechanism is necessary to expose tissue antigens to circulating lymphocytes. The accompanying osteitis is not haphazard, but rather follows the lines of mechanical stress in the bone ${ }^{82}$ In genetically susceptible individuals, such exposed antigens can elicit autoinflammatory and autoimmune reactions. The more extensive oligoclonal expansion of CD8+ $\mathrm{T}$ cells that occurs in patients with AS compared with healthy HLA-B27+ individuals further supports the antigen-specific pathological mechanism of this disease. ${ }^{7,9}$

Histopathological changes are of a fibrocartilaginous inflammatory reaction including hyperosteoclastic, erosive lesions infiltrating the underlying bone marrow. ${ }^{66}$ Further changes include an increased quantity of enthesis fibrocartilage, enthesophytes formed by endochondral ossification, fissures and cracks, and extensive granulation tissue. In humans, enthesophytes range from small lesions at the Achilles and patellar tendons and plantar aponeurosis, to larger spurs forming complete ossification between adjacent vertebral segments with the classic "bamboo spine" appearance. The steps by which these enthesophytes form remain elusive, but a necessary antecedent step includes fibrocartilage cell proliferation. The results of animal studies have demonstrated that capillary invasion from underlying bone marrow creates tunnels that are eventually filled with bone. ${ }^{8}$ Ankylosis of the axial spine tends to begin in the lumbar area and ascends. Cervical spine involvement with development of neck pain occurs as a function of disease duration, with $20 \%$ affected at 5 years and $70 \%$ at 20 years. ${ }^{35}$ The osseous extension or ankylosis is thought to be initiated by the mechanical forces of muscle pulling, and mediated by the interaction between bone morphogenetic proteins, activins, and TGF $\beta$. The cellular infiltrate initially comprises $\mathrm{CD} 68+$ macrophages that yield to predominantly CD8+ T cells in patients with established disease..$^{66,83}$

Sacroiliitis is characterized by synovitis and myxoid bone marrow with formation of pannus and granulation tissue. These processes erode, destroy, and replace articular cartilage and subchondral bone. Paraarticular bone is also thickened by the stimulated osteoblastic activity. The combination of concomitant synovitis, subchondral bone marrow inflammation, and cartilage destruction and regeneration has implicated sacroiliitis in AS as more than simply an extension of the above enthesitis. ${ }^{43}$ The sacroiliac joint inflammation in AS has a predilection for the iliac side of the joint, and this may be due to the greater fibrocartilaginous lining and the greater shear stresses experienced on that side. ${ }^{56}$ Neovascularization is also common, along with proliferating fibroblasts and molecular upregulation of TNF $\alpha$ and TGF $\beta$ transcripts. Bone destruction is mediated mainly by CD68+ macrophages and CD4+ T cells, followed by endochondral ossification and bone ankylosis. ${ }^{13}$ The cellular infiltrate is composed of CD68+ macrophages, CD4+ T cells, B cells, and NK cells. ${ }^{11}$ Although gluteal region discomfort often implicates a sacroiliac joint pathological entity, discomfort in this region can also be complicated by a spasm of the piriformis muscle and compression of the sciatic nerve.

In AS, entheses of the lower limbs are more commonly involved than those of the upper limb. The heel is the most frequent location of enthesitis in AS, with inflammation at the plantar fascia eroding the calcaneus and causing consequent periostitis and bone spur formation. Asymmetrical, oligoarticular peripheral arthritis also develops among most AS patients during the course of their disease. The late changes of ankylosis and osteoarthritis can lead to loss of function and total joint arthroplasty in $8-15 \%$ of patients. ${ }^{46,93}$

Despite the increased ankylosis of joints, patients with AS commonly have decreased bone mineral density with consequent presentations of nontraumatic fractures in young, male patients. Osteoporosis of the femoral neck occurs in one third of patients, with osteopenia afflicting a further $41 \%$. The lower bone mineral density in these patients seems related to the activity and severity of the underlying inflammatory process ${ }^{57}$ although the mechanism remains unclear. Heightened levels of the soluble receptor activator of $\mathrm{N}-\kappa \beta$ ligand promote osteoclast activity despite normal osteoprotegerin levels that antagonize osteoclast activity, creating a homeostatic perturbation towards bone resorption. Other causes of osteoporosis beyond the inflammatory osteoclast activation in this population include corticosteroid use, immobility, and hormonal imbalance. ${ }^{85}$

Appel and coworkers ${ }^{3}$ have established a correlation of histopathological features and magnetic resonance imaging evaluations in 8 patients with AS. The chosen sequence was T2-weighted images with fat saturation in which water appears to have a high intensity. Bone marrow edema of the lumbar spine zygapophyseal joints detected by this examination correlates with interstitial edema on histological examination but not with the underlying inflammatory cell infiltration. The regression of the edemic changes seen on MR imaging has been demonstrated as early as 6 weeks after treatment with disease-modifying anti-TNF $\alpha$ therapy. ${ }^{94}$

\section{Conclusions}

The clinical manifestations of AS are believed to result from a combination of an immunogenetic predisposition and a triggering biomechanical, inflammatory, or infectious event that leads to disease. The precise sequence of the immune activation and consequent histopathological characteristics has remained undefined. Strong associations with the presence of HLA-B27 could result from various molecular abnormalities ranging from the presentation of novel arthritogenic peptides to an abnormal autoimmune stimulation to an anomalous microbial tolerance. The role of an antecedent infection in the onset of AS has not been as clearly established as for other seronegative spondyloarthropathies, although significant evidence of an immunoreactivity against Klebsiella in this patient population may represent a primary pathogenic step. Furthermore, a biomechanical triggering event can initiate either exposure to previously immune-sequestered autoantigens or provide 
a route for bacterial seeding to initiate inflammation. A better comprehension of the sequence of molecular events that actualize AS will facilitate the development of more specific and targeted therapies.

\section{References}

1. Allen RL, O'Callaghan CA, McMichael AJ, Bowness P: Cutting edge: HLA-B27 can form a novel beta 2-microglobulin-free heavy chain homodimer structure. J Immunol 162:5045-5048, 1999

2. Anderson IH, Levine AS, Levitt MD: Incomplete absorption of the carbohydrate in all-purpose wheat flour. N Engl J Med 304: 891-892, 1981

3. Appel H, Loddenkemper C, Grozdanovic Z, Ebhardt H, Dreimann M, Hempfing A, et al: Correlation of histopathological findings and magnetic resonance imaging in the spine of patients with ankylosing spondylitis. Arthritis Res Ther 8: R143, 2006

4. Azuz-Lieberman N, Markel G, Mizrahi S, Gazit R, Hanna J, Achdout $\mathrm{H}$, et al: The involvement of NK cells in ankylosing spondylitis. Int Immunol 17:837-845, 2005

5. Bal A, Unlu E, Bahar G, Aydog E, Eksioglu E, Yorgancioglu R: Comparison of serum IL-1 beta, sIL-2R, IL-6, and TNF-alpha levels with disease activity parameters in ankylosing spondylitis. Clin Rheumatol 26:211-215, 2007

6. Ball EJ, Khan MA: HLA-B27 polymorphism. Joint Bone Spine 68:378-382, 2001

7. Benjamin M, McGonagle D: The anatomical basis for disease localisation in seronegative spondyloarthropathy at entheses and related sites. J Anat 199:503-526, 2001

8. Benjamin M, Rufai A, Ralphs JR: The mechanism of formation of bony spurs (enthesophytes) in the achilles tendon. Arthritis Rheum 43:576-583, 2000

9. Benjamin M, Toumi H, Suzuki D, Redman S, Emery P, McGonagle D: Microdamage and altered vascularity at the enthesis-bone interface provides an anatomic explanation for bone involvement in the HLA-B27-associated spondylarthritides and allied disorders. Arthritis Rheum 56:224-233, 2007

10. Beyeler C, Armstrong M, Bird HA, Idle JR, Daly AK: Relationship between genotype for the cytochrome P450 CYP2D6 and susceptibility to ankylosing spondylitis and rheumatoid arthritis. Ann Rheum Dis 55:66-68, 1996

11. Bollow M, Fischer T, Reisshauer H, Backhaus M, Sieper J, Hamm B, et al: Quantitative analyses of sacroiliac biopsies in spondyloarthropathies: $\mathrm{T}$ cells and macrophages predominate in early and active sacroiliitis - cellularity correlates with the degree of enhancement detected by magnetic resonance imaging. Ann Rheum Dis 59:135-140, 2000

12. Brandt J, Haibel H, Cornely D, Golder W, Gonzalez J, Reddig J, et al: Successful treatment of active ankylosing spondylitis with the anti-tumor necrosis factor alpha monoclonal antibody infliximab. Arthritis Rheum 43:1346-1352, 2000

13. Braun J, Bollow M, Neure L, Seipelt E, Seyrekbasan F, Herbst H, et al: Use of immunohistologic and in situ hybridization techniques in the examination of sacroiliac joint biopsy specimens from patients with ankylosing spondylitis. Arthritis Rheum 38:499-505, 1995

14. Braun J, Bollow M, Remlinger G, Eggens U, Rudwaleit M, Distler A, et al: Prevalence of spondylarthropathies in HLA-B27 positive and negative blood donors. Arthritis Rheum 41:58-67, 1998

15. Braun J, Brandt J, Listing J, Zink A, Alten R, Golder W, et al: Treatment of active ankylosing spondylitis with infliximab: a randomised controlled multicentre trial. Lancet 359:1187-1193, 2002

16. Braun J, Davis J, Dougados M, Sieper J, van der Linden S, van der Heijde D: First update of the international ASAS consensus statement for the use of anti-TNF agents in patients with ankylosing spondylitis. Ann Rheum Dis 65:316-320, 2006
17. Braun J, Pham T, Sieper J, Davis J, van der Linden S, Dougados $\mathrm{M}$, et al: International ASAS consensus statement for the use of anti-tumor necrosis factor agents in patients with ankylosing spondylitis. Ann Rheum Dis 62:817-824, 2003

18. Braun J, Tuszewski M, Ehlers S, Häberle J, Bollow M, Eggens U, et al: Nested polymerase chain reaction strategy simultaneously targeting DNA sequences of multiple bacterial species in inflammatory joint diseases. II. Examination of sacroiliac and knee joint biopsies of patients with spondyloarthropathies and other arthritides. J Rheumatol 24:1101-1105, 1997

19. Brewerton DA, Hart FD, Nicholls A, Caffrey M, James DC, Sturrock RD: Ankylosing spondylitis and HL-A 27. Lancet 1: 904-907, 1973

20. Brophy S, Hickey S, Menon A, Taylor G, Bradbury L, Hamersma $\mathrm{J}$, et al: Concordance of disease severity among family members with ankylosing spondylitis? J Rheumatol 31:1775-1778, 2004

21. Brown MA: Non-major-histocompatibility-complex genetics of ankylosing spondylitis. Best Pract Res Clin Rheumatol 20: 611-621, 2006

22. Brown MA, Edwards S, Hoyle E, Campbell S, Laval S, Daly AK, et al: Polymorphisms of the CYP2D6 gene increase susceptibility to ankylosing spondylitis. Hum Mol Genet 9:1563-1566, 2000

23. Brown MA, Kennedy LG, Darke C, Gibson K, Pile KD, Shatford JL, et al: The effect of HLA-DR genes on susceptibility to and severity of ankylosing spondylitis. Arthritis Rheum 41:460-465, 1998

24. Brown MA, Kennedy LG, MacGregor AJ, Darke C, Duncan E, Shatford JL, et al: Susceptibility to ankylosing spondylitis in twins: the role of genes, HLA, and the environment. Arthritis Rheum 40:1823-1828, 1997

25. Brown MA, Pile KD, Kennedy LG, Calin A, Darke C, Bell J, et al: HLA class I associations of ankylosing spondylitis in the white population in the United Kingdom. Ann Rheum Dis 55:268-270, 1996

26. Calin A, Marder A, Becks E, Burns T: Genetic differences between B27 positive patients with ankylosing spondylitis and B27 positive healthy controls. Arthritis Rheum 26:1460-1464, 1983

27. Cauli A, Dessole G, Fiorillo MT, Vacca A, Mameli A, Bitti P, et al: Increased level of HLA-B27 expression in ankylosing spondylitis patients compared with healthy HLA-B27-positive subjects: a possible further susceptibility factor for the development of disease. Rheumatology (Oxford) 41:1375-1379, 2002

28. Chan AT, Kollnberger SD, Wedderburn LR, Bowness P: Expansion and enhanced survival of natural killer cells expressing the killer immunoglobulin-like receptor KIR3DL2 in spondylarthritis. Arthritis Rheum 52:3586-3595, 2005

29. Chen $\mathrm{CH}$, Lin KC, Yu DT, Yang C, Huang F, Chen HA, et al: Serum matrix metalloproteinases and tissue inhibitors of metalloproteinases in ankylosing spondylitis: MMP-3 is a reproducibly sensitive and specific biomarker of disease activity. Rheumatology (Oxford) 45:414-420, 2006

30. Dangoria NS, DeLay ML, Kingsbury DJ, Mear JP, UchanskaZiegler B, Ziegler A, et al: HLA-B27 misfolding is associated with aberrant intermolecular disulfide bond formation (dimerization) in the endoplasmic reticulum. J Biol Chem 277: 23459-23468, 2002

31. Del Porto P, D'Amato M, Fiorillo MT, Tuosto L, Piccolella E, Sorrentino R: Identification of a novel HLA-B27 subtype by restriction analysis of a cytotoxic gamma delta $\mathrm{T}$ cell clone. J Immunol 153:3093-3100, 1994

32. Duftner C, Goldberger C, Falkenbach A, Würzner R, Falkensammer B, Pfeiffer KP, et al: Prevalence, clinical relevance and characterization of circulating cytotoxic CD4+CD28- T cells in ankylosing spondylitis. Arthritis Res Ther 5:R292-R300, 2003

33. Ebringer A, Wilson C: HLA molecules, bacteria and autoimmunity. J Med Microbiol 49:305-311, 2000

34. Ebringer R, Cawdell D, Ebringer A: Klebsiella pneumoniae and 
acute anterior uveitis in ankylosing spondylitis. Br Med J 1:383, 1979

35. El Maghraoui A, Bensabbah R, Bahiri R, Bezza A, Guedira N, Hajjaj-Hassouni N: Cervical spine involvement in ankylosing spondylitis. Clin Rheumatol 22:94-98, 2003

36. Falk K, Rötzschke O, Takiguchi M, Gnau V, Stevanovic S, Jung G, et al: Peptide motifs of HLA-B58, B60, B61, and B62 molecules. Immunogenetics 41:165-168, 1995

37. Fielder M, Pirt SJ, Tarpey I, Wilson C, Cunningham P, Ettelaie C, et al: Molecular mimicry and ankylosing spondylitis: possible role of a novel sequence in pullulanase of Klebsiella pneumoniae. FEBS Lett 369:243-248, 1995

38. Fiorillo MT, Greco G, Maragno M, Potolicchio I, Monizio A, Dupuis ML, et al: The naturally occurring polymorphism Asp116$>$ His116, differentiating the ankylosing spondylitis-associated HLA-B*2705 from the non-associated HLA-B*2709 subtype, influences peptide-specific CD8 T cell recognition. Eur J Immunol 28:2508-2516, 1998

39. Fiorillo MT, Maragno M, Butler R, Dupuis ML, Sorrentino R: CD8(+) T-cell autoreactivity to an HLA-B27-restricted self-epitope correlates with ankylosing spondylitis. J Clin Invest 106: 47-53, 2000

40. Fiorillo MT, Rückert C, Hülsmeyer M, Sorrentino R, Saenger W, Ziegler A, et al: Allele-dependent similarity between viral and self-peptide presentation by HLA-B27 subtypes. J Biol Chem 280:2962-2971, 2005

41. Fraile A, Nieto A, Matarán L, Martín J: HSP70 gene polymorphisms in ankylosing spondylitis. Tissue Antigens 51:382-385, 1998

42. Fraile A, Nieto A, Vinasco J, Beraún Y, Martín J, Matarán L: Association of large molecular weight proteasome 7 gene polymorphism with ankylosing spondylitis. Arthritis Rheum 41: 560-562, 1998

43. François RJ, Gardner DL, Degrave EJ, Bywaters EG: Histopathologic evidence that sacroiliitis in ankylosing spondylitis is not merely enthesitis. Arthritis Rheum 43:2011-2024, 2000

44. Frauendorf E, von Goessel H, May E, Märker-Hermann: HLAB27-restricted cells from patients with ankylosing spondylitis recognize peptides from $\mathrm{B} * 2705$ that are similar to bacteriaderived peptides. Clin Exper Immunol 134:35-359, 2003.

45. Glant TT, Bárdos T, Vermes C, Chandrasekaran R, Valdéz JC, Otto JM, et al: Variations in susceptibility to proteoglycan-induced arthritis and spondylitis among $\mathrm{C} 3 \mathrm{H}$ substrains of mice: evidence of genetically acquired resistance to autoimmune disease. Arthritis Rheum 44:682-692, 2001

46. Gran JT, Skomsvoll JF: The outcome of ankylosing spondylitis: a study of 100 patients. Br J Rheumatol 36:766-771, 1997

47. Gratacós J, Collado A, Filella X, Sanmartí R, Cañete J, Llena J, et al: Serum cytokines (IL-6, TNF-alpha, IL-1 beta and IFN-gamma) in ankylosing spondylitis: a close correlation between serum IL-6 and disease activity and severity. Br J Rheumatol 33:927-931, 1994

48. Haibel H, Rudwaleit M, Listing J, Sieper J: Open label trial of anakinra in active ankylosing spondylitis over 24 weeks. Ann Rheum Dis 64:296-298, 2005

49. Hamersma J, Cardon LR, Bradbury L, Brophy S, van der HorstBruinsma I, Calin A, et al: Is disease severity in ankylosing spondylitis genetically determined? Arthritis Rheum 44: 1396-1400, 2001

50. Harding HP, Calfon M, Urano F, Novoa I, Ron D: Transcriptional and translational control in the Mammalian unfolded protein response. Annu Rev Cell Dev Biol 18:575-599, 2002

51. Howe HS, Cheung PL, Kong KO, Badsha H, Thong BY, Leong $\mathrm{KP}$, et al: Transforming growth factor beta- 1 and gene polymorphisms in oriental ankylosing spondylitis. Rheumatology (Oxford) 44:51-54, 2005

52. Huppertz HI, Heesemann J: Invasion and persistence of Salmonella in human fibroblasts positive or negative for endogenous HLA B27. Ann Rheum Dis 56:671-676, 1997
53. Husby G, Tsuchiya N, Schwimmbeck PL, Keat A, Pahle JA, Oldstone MB, et al: Cross-reactive epitope with Klebsiella pneumoniae nitrogenase in articular tissue of HLA-B27+ patients with ankylosing spondylitis. Arthritis Rheum 32:437-445, 1989

54. Jaakkola E, Crane AM, Laiho K, Herzberg I, Sims AM, Bradbury $\mathrm{L}$, et al: The effect of transforming growth factor beta1 gene polymorphisms in ankylosing spondylitis. Rheumatology (Oxford) 43:32-38, 2004

55. Jardetzky TS, Lane WS, Robinson RA, Madden DR, Wiley DC: Identification of self peptides bound to purified HLA-B27. Nature 353:326-329, 1991

56. Kampen WU, Tillmann B: Age-related changes in the articular cartilage of human sacroiliac joint. Anat Embryol 198:505-513, 1998

57. Kim HR, Kim HY, Lee SH: Elevated serum levels of soluble receptor activator of nuclear factors-kappaB ligand (sRANKL) and reduced bone mineral density in patients with ankylosing spondylitis (AS). Rheumatology (Oxford) 45:1197-1200, 2006

58. Kollnberger S, Bird L, Sun MY, Retiere C, Braud VM, McMichael A, et al: Cell-surface expression and immune receptor recognition of HLA-B27 homodimers. Arthritis Rheum 46:2972-2982, 2002

59. Kollnberger S, Bird LA, Roddis M, Hacquard-Bouder C, Kubagawa H, Bodmer HC, et al: HLA-B27 heavy chain homodimers are expressed in HLA-B27 transgenic rodent models of spondyloarthritis and are ligands for paired Ig-like receptors. J Immunol 173:1699-1710, 2004

60. Kollnberger S, Chan A, Sun MY, Chen LY, Wright C, di Gleria $\mathrm{K}$, et al: Interaction of HLA-B27 homodimers with KIR3DL1 and KIR3DL2, unlike HLA-B27 heterotrimers, is independent of the sequence of bound peptide. Eur J Immunol 37:1313-1322, 2007

61. Kuon W, Holzhütter HG, Appel H, Grolms M, Kollnberger S, Traeder A, et al: Identification of HLA-B27-restricted peptides from the Chlamydia trachomatis proteome with possible relevance to HLA-B27-associated diseases. J Immunol 167: 4738-4746, 2001

62. Kuon W, Kuhne M, Busch DH, Atagunduz P, Seipel M, Wu P, et al: Identification of novel human aggrecan $\mathrm{T}$ cell epitopes in HLA-B27 transgenic mice associated with spondyloarthropathy. J Immunol 173:4859-4866, 2004

63. Kuon W, Lauster R, Böttcher U, Koroknay A, Ulbrecht M, Hartmann M, et al: Recognition of chlamydial antigen by HLAB27-restricted cytotoxic T cells in HLA-B*2705 transgenic CBA (H-2k) mice. Arthritis Rheum 40:945-954, 1997

64. Kuon W, Sieper J: Identification of HLA-B27-restricted peptides in reactive arthritis and other spondyloarthropathies: computer algorithms and fluorescent activated cell sorting analysis as tools for hunting of HLA-B27-restricted chlamydial and autologous cross-reactive peptides involved in reactive arthritis and ankylosing spondylitis. Rheum Dis Clin North Am 29:595-611, 2003

65. Lai E, Teodoro T, Volchuk A: Endoplasmic reticulum stress: signaling the unfolded protein response. Physiology (Bethesda) 22: 193-201, 2007

66. Laloux L, Voisin MC, Allain J, Martin N, Kerboull L, Chevalier $\mathrm{X}$, et al: Immunohistological study of entheses in spondyloarthropathies: comparison in rheumatoid arthritis and osteoarthritis. Ann Rheum Dis 60:316-321, 2001

67. Laval SH, Timms A, Edwards S, Bradbury L, Brophy S, Milicic $\mathrm{A}$, et al: Whole-genome screening in ankylosing spondylitis: evidence of non-MHC genetic-susceptibility loci. Am J Hum Genet 68:918-926, 2001

68. Le Bon A, Tough DF: Links between innate and adaptive immunity via type I interferon. Curr Opin Immunol 14:432-436, 2002

69. Leirisalo-Repo M, Hannu T, Mattila L: Microbial factors in spondyloarthropathies: insights from population studies. Curr Opin Rheumatol 15:408-412, 2003

70. Liu J, Zhu P, Peng J, Li K, Du J, Gu J, et al: Identification of disease-associated proteins by proteomic approach in ankylosing 
spondylitis. Biochem Biophys Res Commun 357:531-536, 2007

71. López D, García-Hoyo R, López de Castro JA: Clonal analysis of alloreactive $\mathrm{T}$ cell responses against the closely related $\mathrm{B} * 2705$ and $\mathrm{B} * 2703$ subtypes. Implications for HLA-B27 association to spondyloarthropathy. J Immunol 152:5557-5571, 1994

72. López de Castro JA: HLA-B27 and the pathogenesis of spondyloarthropathies. Immunol Lett 108:27-33, 2007

73. Luthra-Guptasarma M, Singh B: HLA-B27 lacking associated beta2-microglobulin rearranges to auto-display or cross-display residues 169-181: a novel molecular mechanism for spondyloarthropathies. FEBS Lett 575:1-8, 2004

74. Madden DR, Gorga JC, Strominger JL, Wiley DC: The structure of HLA-B27 reveals nonamer self-peptides bound in an extended conformation. Nature 353:321-325, 1991

75. Madden DR, Gorga JC, Strominger JL, Wiley DC: The threedimensional structure of HLA-B27 at 2.1-A resolution suggests a general mechanism for tight peptide binding to MHC. Cell 70:1035-1048, 1992

76. Maksymowych WP, Reeve JP, Reveille JD, Akey JM, Buenviaje $\mathrm{H}, \mathrm{O}$ 'Brien L, et al: High-throughput single-nucleotide polymorphism analysis of the IL1RN locus in patients with ankylosing spondylitis by matrix-assisted laser desorption ionization-timeof-flight mass spectrometry. Arthritis Rheum 48:2011-2018, 2003

77. Maksymowych WP, Russell AS: Polymorphism in the LMP2 gene influences the relative risk for acute anterior uveitis in unselected patients with ankylosing spondylitis. Clin Invest Med 18: 42-46, 1995

78. Maksymowych WP, Tao S, Vaile J, Suarez-Almazor M, RamosRemus C, Russell AS: LMP2 polymorphism is associated with extraspinal disease in HLA-B27 negative Caucasian and Mexican Mestizo patients with ankylosing spondylitis. J Rheumatol 27: $183-189,2000$

79. Martínez-González O, Cantero-Hinojosa J, Paule-Sastre P, GómezMagán JC, Salvatierra-Ríos D: Intestinal permeability in patients with ankylosing spondylitis and their healthy relatives. $\mathbf{B r} \mathbf{J}$ Rheumatol 33:644-647, 1994

80. Martínez A, Pacheco-Tena C, Vázquez-Mellado J, Burgos-Vargas R: Relationship between disease activity and infection in patients with spondyloarthropathies. Ann Rheum Dis 63:1338-1340, 2004

81. May E, Dorris ML, Satumtira N, Iqbal I, Rehman MI, Lightfoot E, et al: CD8 alpha beta T cells are not essential to the pathogenesis of arthritis or colitis in HLA-B27 transgenic rats. J Immunol 170: 1099-1105, 2003

82. McGonagle D, Emery P: Enthesitis, osteitis, microbes, biomechanics, and immune reactivity in ankylosing spondylitis. J Rheumatol 27:2302-2304, 2000

83. McGonagle D, Marzo-Ortega H, O'Connor P, Gibbon W, Hawkey P, Henshaw K, et al: Histological assessment of the early enthesitis lesion in spondyloarthropathy. Ann Rheum Dis 61:534-537, 2002

84. Mear JP, Schreiber KL, Münz C, Zhu X, Stevanovic S, Rammensee HG, et al: Misfolding of HLA-B27 as a result of its B pocket suggests a novel mechanism for its role in susceptibility to spondyloarthropathies. J Immunol 163:6665-6670, 1999

85. Meirelles ES, Borelli A, Camargo OP: Influence of disease activity and chronicity on ankylosing spondylitis bone mass loss. Clin Rheumatol 18:364-368, 1999

86. Mielants H, Veys EM, Cuvelier C, de Vos M: Ileocolonoscopic findings in seronegative spondylarthropathies. Br J Rheumatol 27 (2 Suppl):95-105, 1988

87. Monowarul Islam SM, Numaga J, Fujino Y, Masuda K, Ohda H, Hirata R, et al: HLA-DR8 and acute anterior uveitis in ankylosing spondylitis. Arthritis Rheum 38:547-550, 1995

88. Penttinen MA, Heiskanen KM, Mohapatra R, DeLay ML, Colbert RA, Sistonen L, et al: Enhanced intracellular replication of Salmonella enteritidis in HLA-B27-expressing human monocytic cells: dependency on glutamic acid at position 45 in the B pocket of HLA-B27. Arthritis Rheum 50:2255-2263, 2004

89. Ramos M, Paradela A, Vazquez M, Marina A, Vazquez J, Lopez de Castro JA: Differential association of HLA-B*2705 and $\mathrm{B} * 2709$ to ankylosing spondylitis correlates with limited peptide subsets but not with altered cell surface stability. J Biol Chem 277:28749-28756, 2002

90. Rashid T, Ebringer A: Ankylosing spondylitis is linked to Klebsiella - the evidence. Clin Rheumatol 26:858-864, 2007

91. Reveille JD: Major histocompatibility genes and ankylosing spondylitis. Best Pract Res Clin Rheumatol 20:601-609, 2006

92. Reveille JD, Ball EJ, Khan MA: HLA-B27 and genetic predisposing factors in spondyloarthropathies. Curr Opin Rheumatol 13:265-272, 2001

93. Robertson LP, Davis MJ: A longitudinal study of disease activity and functional status in a hospital cohort of patients with ankylosing spondylitis. Rheumatology (Oxford) 43:1565-1568, 2004

94. Rudwaleit M, Baraliakos X, Listing J, Brandt J, Sieper J, Braun J: Magnetic resonance imaging of the spine and the sacroiliac joints in ankylosing spondylitis and undifferentiated spondyloarthritis during treatment with etanercept. Ann Rheum Dis 64: 1305-1310, 2005

95. Rudwaleit M, Siegert S, Yin Z, Eick J, Thiel A, Radbruch A, et al: Low T cell production of TNFalpha and IFNgamma in ankylosing spondylitis: its relation to HLA-B27 and influence of the TNF-308 gene polymorphism. Ann Rheum Dis 60:36-42, 2001

96. Saarinen M, Ekman P, Ikeda M, Virtala M, Grönberg A, Yu DT, et al: Invasion of Salmonella into human intestinal epithelial cells is modulated by HLA-B27. Rheumatology (Oxford) 41: 651-657, 2002

97. Sahly H, Podschun R, Kekow J, Nölle B, Gross WL, Ullmann U: Humoral immune response to Klebsiella capsular polysaccharides in HLA-B27-positive patients with acute anterior uveitis and ankylosing spondylitis. Autoimmunity 28:209-215, 1998

98. Said-Nahal R, Miceli-Richard C, Gautreau C, Tamouza R, Borot N, Porcher R, et al: The role of HLA genes in familial spondyloarthropathy: a comprehensive study of 70 multiplex families. Ann Rheum Dis 61:201-206, 2002

99. Schlosstein L, Terasaki PI, Bluestone R, Pearson CM: High association of an HL-A antigen, W27, with ankylosing spondylitis. N Engl J Med 288:704-706, 1973

100. Scofield RH, Kurien B, Gross T, Warren WL, Harley JB: HLA-B27 binding of peptide from its own sequence and similar peptides from bacteria: implications for spondyloarthropathies. Lancet 345: 1542-1544, 1995

101. Smith JA, Märker-Hermann E, Colbert RA: Pathogenesis of ankylosing spondylitis: current concepts. Best Pract Res Clin Rheumatol 20:571-591, 2006

102. Stone MA, Payne U, Schentag C, Rahman P, Pacheco-Tena C, Inman RD: Comparative immune responses to candidate arthritogenic bacteria do not confirm a dominant role for Klebsiella pneumonia in the pathogenesis of familial ankylosing spondylitis. Rheumatology (Oxford) 43:148-155, 2004

103. Takayanagi H, Kim S, Matsuo K, Suzuki H, Suzuki T, Sato K, et al: RANKL maintains bone homeostasis through c-Fos-dependent induction of interferon-beta. Nature 416:744-749, 2002

104. Takayanagi H, Kim S, Taniguchi T: Signaling crosstalk between RANKL and interferons in osteoclast differentiation. Arthritis Res 4 (3 Suppl): S227-S232, 2002

105. Tan AL, Marzo-Ortega H, O'Connor P, Fraser A, Emery P, McGonagle D: Efficacy of anakinra in active ankylosing spondylitis: a clinical and magnetic resonance imaging study. Ann Rheum Dis 63:1041-1045, 2004

106. Tani Y, Tiwana H, Hukuda S, Nishioka J, Fielder M, Wilson C, et al: Antibodies to Klebsiella, Proteus, and HLA-B27 peptides in Japanese patients with ankylosing spondylitis and rheumatoid arthritis. J Rheumatol 24:109-114, 1997

107. Taurog JD, Richardson JA, Croft JT, Simmons WA, Zhou M, 
Fernández-Sueiro JL, et al: The germfree state prevents development of gut and joint inflammatory disease in HLA-B27 transgenic rats. J Exp Med 180:2359-2364, 1994

108. Theofilopoulos AN, Baccala R, Beutler B, Kono DH: Type I interferons (alpha/beta) in immunity and autoimmunity. Annu Rev Immunol 23:307-336, 2005

109. Timms AE, Crane AM, Sims AM, Cordell HJ, Bradbury LA, Abbott A, et al: The interleukin 1 gene cluster contains a major susceptibility locus for ankylosing spondylitis. Am J Hum Genet 75:587-595, 2004

110. Turner MJ, Sowders DP, DeLay ML, Mohapatra R, Bai S, Smith JA, et al: HLA-B27 misfolding in transgenic rats is associated with activation of the unfolded protein response. $\mathbf{J}$ Immunol 175:2438-2448, 2005

111. van der Linden S, Valkenburg H, Cats A: The risk of developing ankylosing spondylitis in HLA-B27 positive individuals: a family and population study. Br J Rheumatol 22 (4 Suppl):18-19, 1983

112. Vargas-Alarcón G, Gamboa R, Zuñiga J, Fragoso JM, Hernández-Pacheco $\mathrm{G}$, Londoño $\mathrm{J}$, et al: Association study of LMP gene polymorphisms in Mexican patients with spondyloarthritis. Hum Immunol 65:1437-1442, 2004

113. Vargas-Alarcón G, Londoño JD, Hernández-Pacheco G, Gamboa R, Castillo E, Pacheco-Tena C, et al: Heat shock protein 70 gene polymorphisms in Mexican patients with spondyloarthropathies. Ann Rheum Dis 61:48-51, 2002
114. Visse R, Nagase H: Matrix metalloproteinases and tissue inhibitors of metalloproteinases: structure, function, and biochemistry. Circ Res 92:827-839, 2003

115. Wei JC, Tsai WC, Lin HS, Tsai CY, Chou CT: HLA-B60 and B61 are strongly associated with ankylosing spondylitis in HLA-B27-negative Taiwan Chinese patients. Rheumatology (Oxford) 43:839-842, 2004

116. Wendling D, Toussirot E: Anti-TNF-alpha therapy in ankylosing spondylitis. Expert Opin Pharmacother 5:1497-1507, 2004

117. Westman P, Partanen J, Leirisalo-Repo M, Koskimies S: HSP70-hom NcoI polymorphism and HLA-associations in the Finnish population and in patients with ankylosing spondylitis or reactive arthritis. Eur J Immunogenet 21:81-90, 1994

118. Whelan MA, Archer JR: Chemical reactivity of an HLA-B27 thiol group. Eur J Immunol 23:3278-3285, 1993

Manuscript submitted October 16, 2007.

Accepted November 6, 2007.

Address correspondence to: Eve Tsai, M.D., Ph.D., Division of Neurosurgery, The Ottawa Hospital_Civic Campus, C2, 1053 Carling Avenue, Ottawa, Ontario K1Y 4E9, Canada. email:etsai@ ottawahospital.on.ca. 